Original article

\title{
Effect of polishing protocols on the surface roughness of polyetheretherketone
}

\author{
Kosuke Kurahashi, Takashi Matsuda, Yuichi Ishida, and Tetsuo Ichikawa \\ Department of Prosthodontics and Oral Rehabilitation, Tokushima University Graduate School of Biomedical Sciences, Tokushima, Japan
}

(Received December 22, 2018; Accepted March 16, 2019)

\begin{abstract}
The purpose of this study was to evaluate the influence of various polishing protocols on the surface roughness of polyetheretherketone (PEEK) and identify an effective polishing method of dental prostheses at the chairside. The PEEK specimens were assigned to seven groups with different protocols: no additional polishing (NT); polishing using a rubber point (C); polishing using "silky shine" (S); polishing using "aqua blue paste" (A); protocol C followed by protocol S (CS); protocol C followed by protocol A (CA); and protocol C followed by protocols $\mathrm{S}$ and A (CSA). The surface roughness ( $\mathrm{Sa}$ and $\mathrm{Ra}$ ) of the polished surfaces was measured. The surface roughness decreased in the following order of groups: NT, C, S, CS, CSA, CA, and A. In Groups C and S, wide deep pits formed by abrasive grains of $\mathrm{SiC}$ paper were observed, whereas only fine linear structures were observed on the surface in other groups. With respect to the polishing protocol of PEEK, clinically acceptable surface roughness was obtained using a soft polishing brush and agent for more than $3 \mathrm{~min}$.
\end{abstract}

Keywords; polyetheretherketone, dental prostheses, surface treatment, polishing agent

\section{Introduction}

Polyetheretherketone (PEEK) is an engineering plastic material widely utilized in industrial products owing to its stable physical properties and high abrasion resistance. It has been increasingly employed as a biomaterial for orthopedic and spine cages. In the field of dentistry, various PEEK applications, such as manufacturing implant bodies, implant superstructures, crowns, fixed partial dentures, and frameworks for removable dentures, have been implemented [1-4]. The demand for dental prostheses prepared using such materials will increase in the future due to increasing precious metal prices and problems of dental metal allergies.

A smooth surface is required for dental prostheses to facilitate tongue feeling and dental plaque adhesion to the dental prostheses. Even if it is sufficiently polished at the laboratory side, the surface of the prosthesis often needs to be polished again at the chairside post adjustment. It is reported that humans can distinguish between differences in roughness values of at least $0.5 \mu \mathrm{m}$ [5], and the surface roughness of the final polished prosthesis should not exceed $0.2 \mu \mathrm{m}$, which is the threshold value for enabling dental plaque adhesion [6,7]. In addition, a rough occlusal surface results in a smaller occlusal contact area or mating surface (i.e., the real contact area), thereby increasing the influence of the abrasive wear. Therefore, polishing the surface of dental prostheses is necessary to decrease the surface roughness to the maximum extent.

The information available on polishing PEEK is limited, with only two studies involving both the laboratory and at the chairside [8,9]. However, there are various types of PEEK, and the available literature is unsatisfactory owing to a lack of comparison with polishing conditions of other dental materials. The purpose of this study was to evaluate the influence of various polishing protocols on the surface roughness of PEEK and identify an effective polishing method of dental prostheses at the chairside.

Correspondence to Dr. Kosuke Kurahashi, Department of Prosthodontics and Oral Rehabilitation, Tokushima University Graduate School of Biomedical Sciences, 3-18-15 Kuramoto, Tokushima 770-8504, Japan

Fax:+81-88-633-7461 E-mail: kosukekurah@gmail.com

Color figures can be viewed in the online issue at J-STAGE.

doi.org/10.2334/josnusd.18-0473

DN/JST.JSTAGE/josnusd/18-0473

\section{Materials and Methods}

\section{Materials}

Table 1 shows the materials prepared and used in this study: non-filler-type PEEK; two types of rotating polishing instruments, the abrasive rubber point and the soft polishing brush; and two types of polishing agents, a liquid-type "silky shine" and a paste-type "aqua blue paste."

\section{Specimen preparation}

PEEK specimens were prepared as cylinders of 10-mm diameter and 10 -mm height. The specimens were designed on a computer and machinemilled (RXP500 DSC, Röders GmbH, Soltau, Germany). All specimens were manually trimmed, and the bases of the cylinders were polished under water using 800 -grit abrasive $\mathrm{SiC}$ paper, followed by ultrasonic cleaning in $70 \%$ isopropanol for $15 \mathrm{~min}$. Finally, all specimens were washed three times with distilled water.

\section{Surface treatment modalities}

Six PEEK surface-polishing protocols were prepared, and all procedures were randomly performed by a single practitioner (K.K.) to minimize outcome variability.

\section{NT: No additional polishing}

C: Polishing using a rubber point for $1 \mathrm{~min}$ at a rotation speed of 20,000 rpm

CS: Polishing using a rubber point for $1 \mathrm{~min}$ at 20,000 rpm, followed by polishing using "silky shine" and a soft brush for $1 \mathrm{~min}$ at $10,000 \mathrm{rpm}$ CSA: Polishing using a rubber point for $1 \mathrm{~min}$ at $20,000 \mathrm{rpm}$, followed by polishing using "silky shine" and a soft brush for $30 \mathrm{~s}$ at 10,000 rpm and polishing using "aqua blue paste" and a soft brush for $30 \mathrm{~s}$ at 10,000 rpm (in that order)

CA: Polishing using a rubber point for $1 \mathrm{~min}$ at 20,000 rpm, followed by polishing using "aqua blue paste" and a soft brush for $1 \mathrm{~min}$ at $10,000 \mathrm{rpm}$

S: Polishing using "silky shine" and a soft brush for $3 \mathrm{~min}$ at 10,000 rpm

A: Polishing using "aqua blue paste" and a soft brush for 3 min at $10,000 \mathrm{rpm}$

All rotating polishing instruments were attached to a dental micromotor (EWL K11, KaVo Dental, Biberach, Germany). Polishing was repeated by adding the respective polishing paste every $30 \mathrm{~s}$. The rotation number and polishing time were determined based on the operation manual of the polishing agents and previous literature, respectively.

The specimens were washed with distilled water and dried after every polishing step. Post polishing, all specimens were ultrasonically cleaned in $70 \%$ isopropanol for $15 \mathrm{~min}$, washed three times with distilled water, and then air-dried.

Ten specimens were prepared for each of the seven conditions mentioned above.

\section{Surface roughness measurement}

The specimens' mean surface height (Sa) and the assessed surface profile's mean deviation $(\mathrm{Ra})$ were measured using a laser microscope (Optelics Hybrid, Lasertec Corp., Yokohama, Japan). Three points per base surface were measured, and the median value was used as the representative value of the specimen. Ra, the most widely used parameter in evaluating surface roughness, presents the average surface roughness in two dimensions, and $\mathrm{Sa}$ is obtained by extending $\mathrm{Ra}$ in three dimensions; thus, the influence of directional scratches becomes very small, making it possible to obtain a 
Table 1 Materials used

\begin{tabular}{lllll}
\hline Material & Trade name & Manufacturer & Lot number & Composition \\
\hline PEEK & JUVORA Dental Disc & Invibio Biomaterial Solutions, Lancashire, UK & Not registered & Polyetheretherketone \\
Abrasive rubber point & CeraMaster HP 13S & Shofu Inc., Kyoto, Japan & 1217057 & Diamond particle, synthetic rubber \\
Soft polishing brush & Flannel Disks No. 102 & Polirapid, Singen, Germany & $1117 / 051$ & Flannel \\
Polishing agent & Silky shine & Yamahachi Dental Mfg., Co. Gamagori, Japan & 13066 & Water, naphtha, aluminum silicate \\
Polishing agent & Aqua blue paste & Quest Corp., Komatsushima, Japan & 70735 & Water, ammonium oxide, water-soluble solvent, surfactant \\
\hline
\end{tabular}

Table 2 Surface roughness

\begin{tabular}{|c|c|c|c|c|}
\hline \multirow[b]{2}{*}{$\begin{array}{l}\text { Polishing } \\
\text { Group }\end{array}$} & \multicolumn{2}{|c|}{$\mathrm{Sa}(\mu \mathrm{m})$} & \multicolumn{2}{|c|}{$\mathrm{Ra}(\mu \mathrm{m})$} \\
\hline & $\begin{array}{c}\text { Mean } \pm \\
\text { Standard deviation }\end{array}$ & $\begin{array}{c}95 \% \\
\text { Confidence interval }\end{array}$ & $\begin{array}{c}\text { Mean } \pm \\
\text { Standard deviation }\end{array}$ & $\begin{array}{c}95 \% \\
\text { Confidence interval }\end{array}$ \\
\hline NT & $0.693 \pm 0.084^{\mathrm{ABCDEF}}$ & $0.633-0.754$ & $0.653 \pm 0.109^{\text {abcdef }}$ & $0.575-0.730$ \\
\hline $\mathrm{C}$ & $0.082 \pm 0.012^{\mathrm{ADHJJK}}$ & $0.073-0.090$ & $0.080 \pm 0.017^{\text {aghijk }}$ & $0.068-0.092$ \\
\hline CS & $0.018 \pm 0.004^{\mathrm{BGL}}$ & $0.015-0.021$ & $0.018 \pm 0.006^{\mathrm{bgl}}$ & $0.014-0.022$ \\
\hline CSA & $0.016 \pm 0.005^{\mathrm{CH}}$ & $0.013-0.020$ & $0.016 \pm 0.005^{\mathrm{chm}}$ & $0.013-0.020$ \\
\hline $\mathrm{CA}$ & $0.015 \pm 0.004^{\mathrm{DIM}}$ & $0.013-0.018$ & $0.012 \pm 0.004^{\text {dio }}$ & $0.009-0.015$ \\
\hline $\mathrm{S}$ & $0.028 \pm 0.012^{\mathrm{ENN}}$ & $0.019-0.037$ & $0.031 \pm 0.014^{\text {ejop }}$ & $0.021-0.042$ \\
\hline
\end{tabular}
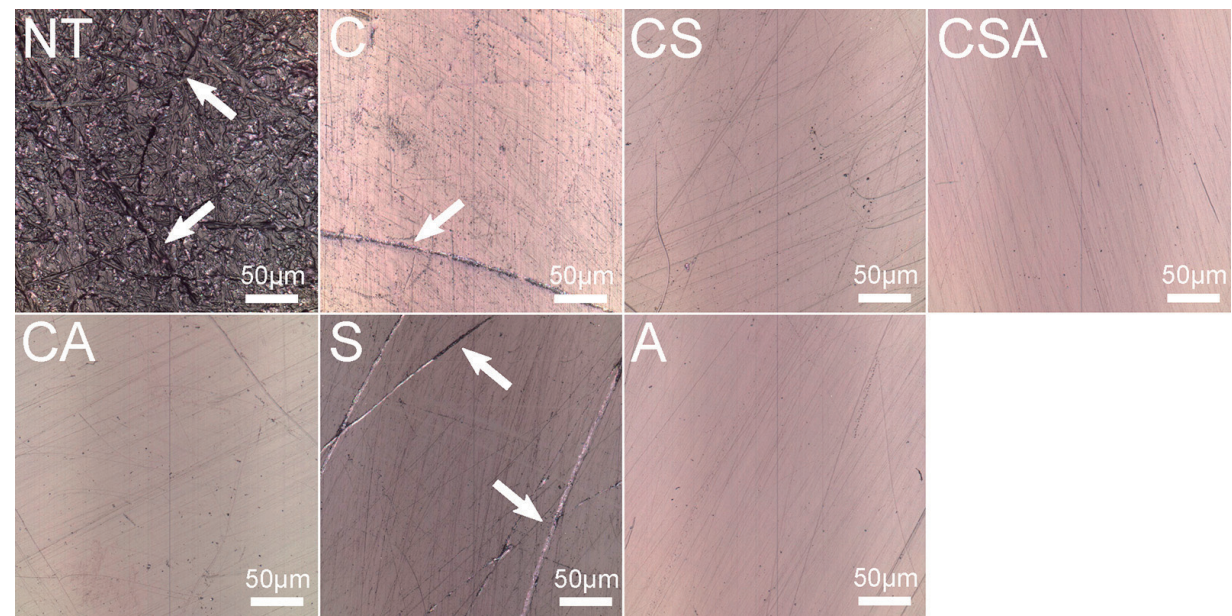

Fig. 1 Two-dimensional images of PEEK surfaces for each polishing protocol, obtained using a laser microscope. Arrows in the images for Groups NT, C, and S show deep pits on each surface. NT, no additional polishing; C, polishing using a rubber point for 1 min at 20,000 rpm; S, polishing using "silky shine" and a soft brush for $3 \mathrm{~min}$ at $10,000 \mathrm{rpm}$
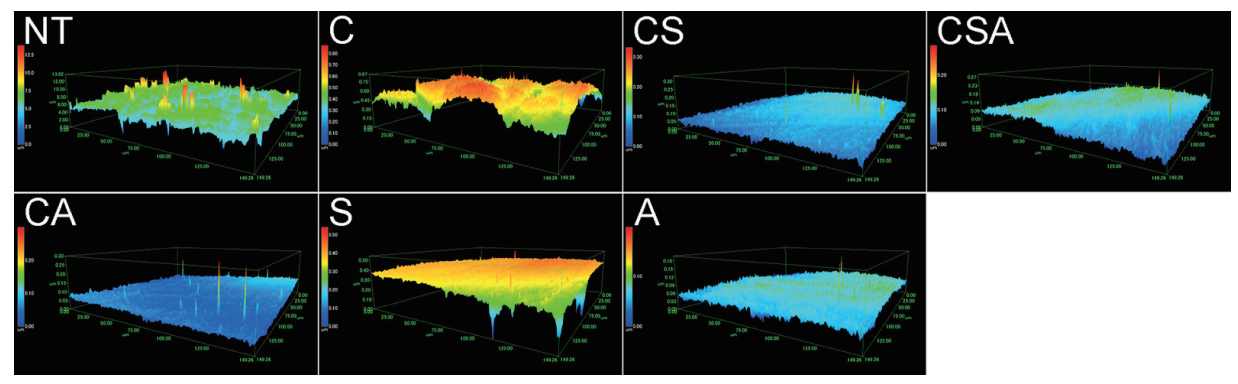

Fig. 2 Color-mapped three-dimensional images of PEEK surfaces for each polishing protocol, obtained using a laser microscope. Colors indicate the height of the scanned area: blue and red indicate low and high distances from a mean horizontal plane.

stable result.

The mean values of the seven groups were compared using the KruskalWallis and Games-Howell post-hoc test. A significance level of 0.05 was used. The data were analyzed using the IBM SPSS Statistics, Version 24.0 software package (IBM Corp., Armonk, NY, USA).

\section{Results}

Table 2 shows the Sa and Ra values for every polishing protocol. Sa and Ra for Group NT showed the largest values, $0.69 \mu \mathrm{m}$ and $0.65 \mu \mathrm{m}$, respectively. These values were more than $0.5 \mu \mathrm{m}$, which represents recognizable roughness. Among the polished groups, surface roughness decreased in the following order: Groups C, S, CS, CSA, CA, and A. The surface roughness of Groups $\mathrm{C}$ and $\mathrm{S}$ exceeded the threshold value of $0.2 \mu \mathrm{m}$, whereas that of the other groups was below $0.2 \mu \mathrm{m}$, which is the threshold for bacterial adherence.

The surface roughness of the six polished groups was significantly lower than that of Group NT. Furthermore, the surface roughness of Group $\mathrm{C}$ was significantly higher than those of the other five polished groups. The Sa value of Group A was significantly lower than those of Groups CS, CA, and $\mathrm{S}$, whereas its Ra value was significantly lower than those of Groups $\mathrm{CS}, \mathrm{CSA}$, and $\mathrm{S}$.

The two-dimensional images captured using the laser microscope are shown in Fig. 1. In Group NT, roughness was observed throughout the surface. In Groups $\mathrm{C}$ and $\mathrm{S}$, wide deep pits formed by abrasive grains of $\mathrm{SiC}$ paper were captured on the images, whereas only fine linear structures were observed on the surfaces in the other groups. Three-dimensional color-mapped images of the surfaces in Fig. 2 support this result. The find- 
ings shown in Fig. 1 can be quantitatively evaluated. The forms of deep pits were observed in Group NT and C. Surface waviness appeared in the Group C. Groups CS, CSA, CA, and A showed similar surface patterns.

\section{Discussion}

Previous studies regarding PEEK polishing have focused only on a fillercontaining-type PEEK (BioHPP). The PEEK used in the present study is non-filler type having high purity and excellent biocompatibility also in addition to stability at the nanoscale. There is no report on the polishing of non-filler type PEEK. Therefore, the present study focused on the polishing protocols for such PEEKs, which can be made easily available on the chairside. Six different types of polishing protocols were employed in this study, with acceptable polishing times and an acceptable surface roughness of approximately $0.2 \mu \mathrm{m}$.

Sturz et al. reported the average values of $\mathrm{Ra}$ and $\mathrm{Sa}$ for polishing fillercontaining PEEK using 1,000-grit $\mathrm{SiC}$ paper to be $0.277 \mu \mathrm{m}$ and $0.547 \mu \mathrm{m}$, respectively [8]. By adding high-gloss finish using a 1- $\mu \mathrm{m}$ diamond paste applied via a cotton buff, the authors decreased the Ra and Sa values to $0.073 \mu \mathrm{m}$ and $0.148 \mu \mathrm{m}$, respectively. Furthermore, the Ra and Sa values of $50 \%$ inorganic nano-filled dimethylacrylate polished using the same protocol were $0.399 \mu \mathrm{m}$ and $0.108 \mu \mathrm{m}$, respectively. Therefore, it has been suggested that PEEK becomes smoother than composite resin when both materials are polished with the diamond paste using the cotton buff. Heimer et al. also evaluated the surface roughness of the same type of PEEK, polished using P1,200 and P4,000 SiC abrasive papers as controls, through laboratory and chairside polishing protocols and found surface roughness to be $0.032 \pm 0.003 \mu \mathrm{m}$ [9]. Polishing with mops using Abraso polishing paste (duration: $1 \mathrm{~min}$; rotation speed: $3,000 \mathrm{rpm}$ ) as the laboratory-side protocol yielded the lowest surface roughness of $0.034 \pm 0.010 \mu \mathrm{m}$. The surface roughness obtained upon polishing using a Prisma-gloss polishing paste (duration: $40 \mathrm{~s}$ only paste and $20 \mathrm{~s}$ paste with water in small amounts; rotation speed: $8,000 \mathrm{rpm}$ ) as the chairside protocol yielded the lowest surface roughness of $0.072 \pm 0.009 \mu \mathrm{m}$. The polishing effect is reciprocally affected by the hardness of the PEEK, which is almost equal to or slightly more than that of acrylic resin, and polishing materials. The researchers speculate that the surface irregularities of PEEK are reduced by polishing because of the cutting action of the diamond particles in the rubber point; a similar effect is achieved by the surface plastic flow of the ingredients in protocols S and A. However, as "silky shine" and the "aqua blue paste" in these protocols are in the liquid/paste form and their hardness properties remain confidential, it is difficult to discuss their polishing effect from the perspective of material hardness.

In this study, the three-body abrasive wear mode of PEEK surface in Groups CS, CSA, CA, A, and S showed lower surface roughness than the two-body mode in Group C, as suggested in the two aforementioned previous studies [8,9]. Further, the effect of "silky shine" for thermoplastics was smaller than that of the polish used in the other five polished groups, and the surface roughness for the three polishing protocols that included "silky shine," CS, CSA, and S, was high. In contrast, protocols that used the "aqua blue paste" for the resin/metal offered more effective polishing, especially when only the "aqua blue paste" was used for a long duration in Group A.

Compared with the polished surface roughness of other polymer materials used in dental prostheses, it has been reported that the average roughness of the thermoplastic resin polished using a paste-type polishing agent/compound in combination with the buff ranged between 0.12 and $0.28 \mu \mathrm{m}$ [10-12]. In the present study, as the surface roughness of the six polished groups of PEEK was lower than that reported in previous works, the researchers suggest that the surface properties of PEEK are better than those of other thermoplastic resins. Additionally, it has been reported that the average roughness of acrylic resin polished using a paste-type agent/ slurry ranged between 0.02 and $0.20 \mu \mathrm{m}$ [13-16]; these values are larger than those of the five polished PEEK groups. It has also been reported that $\mathrm{Ra}$ and $\mathrm{Sa}$ values of the resin composites used as restorative materials that need to be polished in the oral cavity range between 0.1 and $0.3 \mu \mathrm{m}$ and between 0.13 and $0.23 \mu \mathrm{m}$, respectively [17-21]. The abovementioned inferences and results obtained in this study suggest that PEEK can be polished into a sufficiently smooth surface for use as a dental prosthesis.
Although a multiple-step polishing protocol can provide a smoother surface, a single-step polishing protocol is preferable at the chairside to save time and expense [20]. In the actual polishing procedure, the following measures are also needed: reducing frictional resistance and minimizing change in temperature of the material surface during polishing, avoiding splashing the polishing agent, and ensuring that the polishing agent can be easily washed away after polishing to avoid bacterial adherence. Furthermore preferably, polishing should be performed while adding a soluble paste, such as the "aqua blue paste," at regular intervals.

Thus, it can be concluded that clinically acceptable surface roughness of PEEK was obtained using polishing agents with a soft polishing brush; in particular, the polishing agent for resin/metal is more effective than that for thermoplastic resin.

\section{Acknowledgments}

PEEK materials were provided free of charge by Invibio Biomaterial Solutions. This work was supported by JSPS KAKENHI Grant Number JP16K11597.

\section{Conflict of interest}

The authors have no conflict of interest in the companies whose materials are mentioned in the article.

\section{References}

1. Panayotov IV, Orti V, Cuisinier F, Yachouh J (2016) Polyetheretherketone (PEEK) for medical applications. J Mater Sci Mater Med 27, 118

2. Zoidis P, Papathanasiou I, Polyzois G (2016) The use of a modified poly-ether-ether-ketone (PEEK) as an alternative framework material for removable dental prostheses. A clinical report. J Prosthodont 25, 580-584.

3. Wagner C, Stock V, Merk S, Schmidlin PR, Roos M, Eichberger M et al. (2018) Retention load of telescopic crowns with different taper angles between cobalt-chromium and polyetheretherketone made with three different manufacturing processes examined by pull-off test. J Prosthodont 27, 162-168.

4. Harb IE, Abdel-Khalek EA, Hegazy SA (2019) CAD/CAM constructed poly(etheretherketone) (PEEK) framework of kennedy class I removable partial denture: a clinical report. J Prosthodont 28, e595-598.

5. Jones CS, Billington RW, Pearson GJ (2004) The in vivo perception of roughness of restorations. Br Dent J 196, 42-45.

6. Bollen CM, Papaioanno W, Van Eldere J, Schepers E, Quirynen M, van Steenberghe D (1996) The influence of abutment surface roughness on plaque accumulation and periimplant mucositis. Clin Oral Implants Res 7, 201-211.

7. Bürgers R, Gerlach T, Hahnel S, Schwarz F, Handel G, Gosau M (2010) In vivo and in vitro biofilm formation on two different titanium implant surfaces. Clin Oral Implants Res 21, 156-164.

8. Sturz CR, Faber FJ, Scheer M, Rothamel D, Neugebauer J (2015) Effects of various chair-side surface treatment methods on dental restorative materials with respect to contact angles and surface roughness. Dent Mater J 34, 796-813.

9. Heimer S, Schmidlin PR, Roos M, Stawarczyk B (2017) Surface properties of polyetheretherketone after different laboratory and chairside polishing protocols. J Prosthet Dent 117, 419-425.

10. Abuzar MA, Bellur S, Duong N, Kim BB, Lu P, Palfreyman N et al. (2010) Evaluating surface roughness of a polyamide denture base material in comparison with poly (methyl methacrylate). J Oral Sci 52, 577-581.

11. Wieckiewicz M, Opitz V, Richter G, Boening KW (2014) Physical properties of polyamide-12 versus PMMA denture base material. Biomed Res Int 2014, 150298.

12. Moussa AR, Dehis WM, Elboraey AN, ElGabry HS (2016) A comparative clinical study of the effect of denture cleansing on the surface roughness and hardness of two denture base materials. Open Access Maced J Med Sci 4, 476-481.

13. Kuhar M, Funduk N (2005) Effects of polishing techniques on the surface roughness of acrylic denture base resins. J Prosthet Dent 93, 76-85.

14. Gungor H, Gundogdu M, Yesil Duymus Z (2014) Investigation of the effect of different polishing techniques on the surface roughness of denture base and repair materials. J Prosthet Dent 112, 1271-1277.

15. Rao DC, Kalavathy N, Mohammad HS, Hariprasad A, Kumar CR (2015) Evaluation of the surface roughness of three heat-cured acrylic denture base resins with different conventional lathe polishing techniques: a comparative study. J Indian Prosthodont Soc 15, 374-380.

16. Onwubu SC, Vahed A, Singh S, Kanny KM (2017) Reducing the surface roughness of dental acrylic resins by using an eggshell abrasive material. J Prosthet Dent 117, 310-314.

17. Choi MS, Lee YK, Lim BS, Rhee SH, Yang HC (2005) Changes in surface characteristics of dental resin composites after polishing. J Mater Sci Mater Med 16, 347-353.

18. Jung M, Eichelberger K, Klimek J (2007) Surface geometry of four nanofiller and one hybrid composite after one-step and multiple-step polishing. Oper Dent 32, 347-355.

19. Antonson SA, Yazici AR, Kilinc E, Antonson DE, Hardigan PC (2011) Comparison of different finishing/polishing systems on surface roughness and gloss of resin composites. $\mathrm{J}$ Dent 39, e9-17.

20. Ereifej NS, Oweis YG, Eliades G (2013) The effect of polishing technique on 3-D surface roughness and gloss of dental restorative resin composites. Oper Dent 38, E1-12.

21. Pala K, Tekçe N, Tuncer S, Serim ME, Demirci M (2016) Evaluation of the surface hardness, roughness, gloss and color of composites after different finishing/polishing treatments and thermocycling using a multitechnique approach. Dent Mater J 35, 278-289. 